\title{
Malinche e a narrativa histórica feminina no século XXI
}

\section{Malinche and the feminine historical narrative in the $21^{\text {st }}$ century}

Fernanda Aparecida Ribeiro ${ }^{1}$

Possui graduação em Licenciatura em Português Inglês e Espanhol pela Universidade Estadu pela Universidade Estadual de Londrina (2004) doutorado em Letras/Literatura pela UNESP/Assis. Desde agosto de 2010 é professora adjunta en Literatura Hispano-americana na Universidade Federal de Allenas (UNIFAL-MG). Em 2016 estä Ezendo o pos-doutorado
RESUMO: A literatura de autoria feminina tem registrado ultimamente experiências de personagens femininas que transitam entre as esferas privadas e públicas, com o objetivo de desmascarar a subordinação da mulher legitimada pela ideologia patriarcal e pela literatura canônica. Nesse cenário, algumas escritoras têm se destacado na ficção por resgatar figuras históricas que foram esquecidas ou silenciadas ao longo do tempo por uma realidade arbitrária e por um discurso que valoriza o masculino em detrimento ao feminino. Nesse trabalho, o destaque é a personagem Malinche, uma indígena que acompanhou Hernán Cortés na Conquista do México e ficou conhecida como a traidora de seu povo. 0 objetivo desse estudo é apresentar as reflexões e a versão do passado que Laura Esquivel oferece em seu romance Malinche (2006), emaranhando os discursos histórico e literário e fazendo com que sua obra provoque o diálogo com a história de forma "transgressora", pois implica novas visões sobre o discurso instaurado (TROUCHE, 2006). A autora torna-se, assim, uma expoente da literatura escrita por mulheres como sujeitos próprios de seu discurso e que tem como propósito desconstruir o discurso histórico oficial, ao apresentar uma personagem feminina consciente de seus atos e palavras.

PalaVRas-CHAVE: Literatura e Mulher; Literatura e História; Laura Esquivel; Malinche.

ABSTRACT: The literature of feminine authorship lately registered experiences from female characters that circulate between private and public spheres with the aim of taking the mask off the woman's subordination legitimated by the patriarchal ideology and by the canonic literature. In this setting, some writers have stood out in fiction for recovering historical figures that were forgotten or silenced throughout the time by an arbitrary values the male figure in disadvantage of the female figure. In this work, the outstanding is the character Malinche, an indian who took Hernan Cortez to Mexico Conquest and she became well known like the traitor of her people. The aim of this study is to present the reflections and the version of the past that Laura Esquivel offers in her Malinche novel (2006), entangling the historical and literary speech and making her play to provoke the dialogue with the History so that it is "lawbreaking", for implies new versions on the established speech. The writer becomes, thus, an exponent of the written literature by women as own subjects of their discourse and that has as purpose to deconstruct the official historical speech on introducing a female character conscious of her acts and words.

KEYWORDS: Literature and Woman; Literature and History; Laura Esquivel; Malinche. 
$\mathrm{N}^{2}$ as últimas décadas, a literatura escrita por mulheres tem resgatado, principalmente, experiências de personagens femininas que transitam entre as esferas privadas e públicas, bem como heroínas que representam valores e ideologias de suas épocas. Um dos objetivos dessas escritoras é desmascarar a subordinação das mulheres legitimada pela ideologia patriarcal e, pode-se dizer, pela literatura canônica, além de desvendar a manipulação da história para impor determinados princípios e valores na sociedade. Nesse cenário, algumas autoras têm se destacado na ficção por resgatar figuras históricas que ou foram esquecidas e silenciadas ao longo do tempo por uma realidade arbitrária e por um discurso que valoriza o masculino em detrimento do feminino ou por retratar protagonistas que se tornaram emblemas contraditórios em suas culturas.

Essa tendência na literatura contemporânea vem à tona nos anos 70 do século XX, uma década após o início da chamada "segunda onda do feminismo" quando "aparece como um movimento libertário, [...] que luta, sim, por uma nova forma de relacionamento entre homens e mulheres, em que esta última tenha liberdade e autonomia para decidir sobre sua vida e seu corpo." (PINTO, 2010, p. 16). Assim, as mulheres começam a reivindicar o fim da discriminação dos papéis sexuais em todas as áreas da sociedade, inclusive nas artes. As mudanças acarretadas por esses atos fazem com que surja na Teoria da Literatura a Crítica Literária Feminista, com o objetivo de desnudar o patriarcalismo e a repressão dos papéis da mulher na sociedade e nos estudos literários. Em linhas gerais, Lucia Osana Zolin (2005, p. 275) resume essa questão:

Historicamente, o cânone literário, tido como um perene e exemplar conjunto de obras-primas representativas de determinada cultura local, sempre foi constituído pelo homem ocidental, branco, de classe média/ alta; portanto, regulado por uma ideologia que exclui os escritos das mulheres, das etnias não brancas, das chamadas minorias sexuais, dos segmentos sociais menos favorecidos etc. Para a mulher inserir-se nesse universo, foram precisos uma ruptura e o anúncio de uma alteridade em relação a essa visão de mundo centrada no logocentrismo e no falogocentrismo.

São vários os estudos e pesquisadores, no mundo inteiro, que se voltam para a área de estudos Mulher e Literatura. Dentro dessa perspectiva, a Crítica Literária Feminista se divide, basicamente, em três vertentes: a britânica; a francesa e a anglo-americana. Nosso estudo aqui está baseado no último enfoque, que se ocupa, entre outras práticas, da noção de experiência da mulher escritora e da representação da mulher no texto literário. Além disso, a crítica anglo-americana volta-se para a busca de uma identidade própria da mulher e do lugar da diferença na literatura, difundindo e denunciando como o patriarcalismo esteve presente na cultura e na construção do cânone literário.

Uma das principais representantes dessa vertente é a estadunidense Elaine Showalter. Entre seus textos, destacamos "A Literature of Their Own" (1986), no qual analisa as obras de ficção de escritoras inglesas do século XIX e demonstra que o desenvolvimento da tradição seguida pelas autoras é semelhante em qualquer subcultura literária. Ela propõe uma classificação para essa literatura: feminine, feminist e female (palavras que geralmente são traduzidas para o português como feminina, feminista e "da mulher"), demonstrando que as autoras começam a escrever a partir de imitação dos modelos e tradições da literatura dominante (canônica e, por isso, tida como "masculina"), passam por uma fase de protesto a esses moldes e, por último, chegam a uma etapa de identidade e autonomia. Para as estudiosas da literatura escrita por mulheres na América Latina, a maioria das escritoras de nosso continente encontram-se, atualmente, entre a segunda e terceira fases: questionando o discurso dominante e hegemônico e trilhando o caminho da busca da identidade da mulher. 
Entre essas estudiosas, destacamos a professora Márcia Hoppe Navarro (1995, p. 53) que em um de seus textos propõe como exemplo do novo rumo dessa literatura "a nova literatura feminista latino-americana":

pela primeira vez no continente latino-americano, a voz da mulher está sendo ouvida de forma autônoma através de obras literárias que realçam novos aspectos, determinados por mudanças que ocorreram no mundo, a partir dos 70, com os movimentos de liberação da mulher.

Dez anos depois, em um artigo sobre a literatura latino-americana atual, a pesquisadora enfatiza que "o sentido de feminino [...] não como algo pejorativo, que se opõe à feminista, mas sim como algo que soma, recupera e adiciona um lado esquecido da história" (NAVARRO, 2005, p. 197). Ou seja, apesar de Showalter sublinhar uma diferença entre os termos feminina, feminista e "da mulher", o nosso objetivo neste texto não é nos atermos à nomenclatura, mas sim ao seu significado, ou seja, demonstrar o percurso da mulher escritora ao longo dos tempos, que parte de uma etapa de reprodução de padrões estabelecidos por uma sociedade patriarcalista, passa por um período de contestação a esses modelos até chegar ao momento atual, que é de encontrar seu próprio caminho, de redescobrir-se como mulher sujeito na literatura.

Dentro desse cenário dos estudos de Mulher e Literatura, o nosso trabalho se volta para a literatura mexicana a fim de resgatar a escrita feminina sobre uma personalidade da cultura do México que tem surgido, com certa frequência, na ficção contemporânea, de modo a questionar a composição de sua imagem, já que os registros de sua época eram feitos somente pelos homens. Trata-se de Malinche, uma indígena que esteve ao lado de Hernán Cortés durante a Conquista do México e que se tornou, ao longo do tempo, uma figura ambígua na construção da identidade mexicana.
Devemos, aqui, atentar ao fato de que o nome Malinche foi atribuído, primeiramente, a Cortés, segundo relata Bernal Díaz del Castillo (1964) em sua crônica. Todavia, por causa da aproximação do conquistador com a indígena, ela foi e é conhecida até os dias de hoje por este nome ${ }^{1}$. Ainda, segundo o cronista espanhol, o nome dela provavelmente era Malinalli ou Malintzin (diminutivo) e foi batizada pelos espanhóis como Doña Marina. Ela era filha de uma família nobre asteca e seu pai era o cacique do lugar. Após a morte dele, sua mãe casou-se novamente e teve um filho homem. Para que seu irmão se tornasse cacique, sua mãe e padrasto a entregaram para comerciantes que a venderam como escrava para mercadores maias. Por isso, Malinche sabia falar o náhuatl, a língua de seus pais, e a língua maia, de seus amos.

Os caminhos de Malinche e Cortés se cruzaram quando os espanhóis venceram a batalha em Tabasco, em terras maias, e os caciques da região presentearam Cortés com vinte escravas, dentre as quais encontrava-se Malinche. Em San Juan de Ulúa, os espanhóis receberam representantes do governante asteca; para a sorte deles, Malinche traduziu o discurso do náhuatl para o maia para que Jerónimo de Aguilar, um frade espanhol que havia sido prisioneiro dos maias e aprendera a língua deles, pudesse traduzir para seus conterrâneos. Assim, formou-se uma rede de comunicação entre os povos indígenas e espanhóis, com a ajuda de Malinche, que logo aprendeu a língua espanhola e pôde ser a intérprete direta de Cortés.

Para o cronista espanhol, Malinche era uma mulher dotada de muitas qualidades dignificantes como inteligência, fidelidade, valentia, entre outras. Contudo, a historiografia nacionalista do México do século XIX, após a sua independência, para "explicar" a Conquista - de modo a dignificar a cultura indígena e desvalorizar os conquistadores - resolveu procurar culpáveis

Por isso, ao nos referirmos à personagem histórica, utilizaremos o nome Malinche. 
pelo sucesso dos espanhóis: assim, Malinche tornou-se um símbolo emblemático, representou de motor da ruína do império asteca, justamente porque foi a tradutora e amante de Cortés - atitude que foi considerada como "traição" a seu povo pelos estudiosos novecentistas. Dessa maneira, sua imagem passa de dignificante, na crônica de Díaz del Castillo, para uma mulher que não tem valor moral, na visão patriarcalista mexicana do século XIX.

Segundo González Hernández (2002), um dos primeiros autores do século XIX a desvalorizar a imagem de Malinche foi Carlos María de Bustamante, que a descreveu como traidora do seu povo por renegar seu povo (os indígenas) e se entregar como amante ao conquistador. Mas esse autor não é o único a propagar tal conceito negativo; vários outros estudiosos seguiram o mesmo pensamento e, como muitos deles eram também políticos, houve um movimento com o objetivo de

crear la mexicanidad extirpando residuo de colonialismo a través de la negación de todo lo español, [y esto] les llevará a ver en la educación, especialmente en la enseñanza escolar, el principal instrumento de creación de consciencia nacional (GONZÁLEZ HERNÁNDEZ, 2002, p. 91-92).

Nessa linha de pensamento, segundo González Hernández, não foi somente a historiografia que identificou Malinche como traidora de seu povo. A tradição oral ou até mesmo a literatura da época acabaram reproduzindo essa associação: podemos citar os mitos de La Chingada e de La Llorona, ou, no campo literário, o romance histórico anônimo Jicotencal (1826) e as obras teatrais como Xicohténcatl, de Moreno Buenvecino, e Teutila, de Torres Arroyo. Especificamente nas obras ficcionais, Malinche é representada como uma traidora, uma falsa heroína que se alia ao inimigo dos indígenas, em contraposição à personagem Teutila, que encarna todos os valores benéficos que ela não teria.
Ainda em meados do século XX, encontramos autores mexicanos que dão continuidade à reputação negativa de Malinche. Entre eles, destacamos Octavio Paz, escritor, ensaísta e vencedor do Prêmio Nobel de 1990, que em 1950 publica no livro El laberinto de la soledad o ensaio "Los hijos de la Malinche”, no qual nega a participação feminina na construção da identidade nacional mexicana. Para ele, Malinche é o símbolo de La Chingada (o verbo chingar é descrito por Paz com significados que vão de importunar a fazer sexo) e os mexicanos seriam o resultado da união da índia violada e traidora com o seu transgressor.

Márcia Hope Navarro (2011, p. 7) explica que a imagem de mulher indígena e submissa sempre esteve presente na literatura e no imaginário coletivo. Contudo, tratando-se de Malinche, a complexidade se torna maior, pois a indígena teve participação direta na Conquista do México ao ser a intérprete de Cortés. Assim, a consequência está explícita no texto de Octavio Paz que "reafirma el mito de la traición y discute la problemática de 'los hijos de Malinche'. El mestizaje es visto como resultado de la violación por parte del padre y la pasividad de la madre; y el mestizo acaba por tornarse un rechazado".

A tradição mexicana é muito contundente nessa direção e, por isso, como destaca Ana Cruz García (2009, p. 52), diante de

esta exclusión de la mujer en la creación de la nación, no es de extrañar que las primeras escritoras, entre otras Elena Garro y Rosario Castellanos, no consiguieron institucionalizar un discurso alternativo, a pesar de sus intentos constantes por explorar espacios nacionales femeninos más auténticos.

À vista disso, essas e outras escritoras mexicanas, nas últimas décadas, têm se dedicado a explorar o mito de Malinche com o intuito de romper a visão hegemônica da indígena e apresentar um novo significado para suas ações. 
Além de Elena Garro e Rosario Castellanos, podemos citar também Marisol Martín del Campo, Fanny del Río, Marcela del Río, Helena Alberú de Villava e, especialmente, Laura Esquivel $(1950)^{2}$ como escritoras que se destacam por estarem inseridas em uma literatura escrita por mulheres como sujeitos próprios de seu discurso e que tem como propósito desconstruir o discurso histórico oficial, ao apresentar uma personagem feminina consciente de seus atos e palavras, entrelaçando, assim, "una imagen pluri-identitaria de la mujer, de la sociedad y de la realidad latinoamericana” (MEDEIROS-LICHEM, 2006, p. 15).

Sobre os diversos significados que foram agregados à imagem de Malinche, Sandra Messinger Cypess (1991, p. 5) afirma de que se trata de

a continually enlarging palimpsest of mexican cultural identity whose layers of meaning have accrued through the years. With each generation the sign «La Malinche» has added diverse interpretations of her identity, role, and significance for individuals and for Mexico.

Nesse sentido, a imagem de Malinche se faz em uma rede intertextual, que começa com as crônicas de Conquista, passa pelos discursos nacionalistas do século XIX e chega ao final do século XX com diversas facetas, algumas delas incompatíveis entre si. A autora assinala que Malinche é um símbolo transnacional porque motiva a discussão de questões próprias às mulheres, como maternidade, presença feminina em questões políticas e de guerra, bem como de identidade. São esses tópicos que podemos encontrar na literatura, nas últimas décadas, escrita por mulheres no México que re-interpretam o mito de Malinche na cultura e história de seu povo.

\footnotetext{
2 Nossa intenção aqui não é fazer um inventário de todas as escritoras mexicanas que escreveram sobre Malinche, mas demonstrar como a personagem histórica se faz presente na literatura de autoria dessa vertente.
}

Ana Cruz García, conforme citado anteriormente, menciona o intento de Elena Garro (que foi esposa de Octavio Paz) e de Rosario Castellanos em abrir um novo trajeto para a voz feminina na literatura mexicana. Nesse momento, faremos um recorte sobre a personagem Malinche, foco de nossa pesquisa, apreciando, ainda que superficialmente, as obras das duas autoras citadas por Cruz García, para que possamos ter uma compreensão de como Laura Esquivel faz parte da continuidade de um grupo de mulheres escritoras que reivindicam para a literatura a possibilidade de reinterpretar a história sobre outro viés - o olhar feminino -, mas sem esquecer-nos de que há outras autoras que trilharam o mesmo caminho nesse ínterim.

Da primeira autora citada por Cruz García, destacamos o conto "La culpa es de los Tlaxcaltecas", publicado na coleção La semana de colores (1964), o qual recupera a lenda de Malinche, ainda que não apareça seu nome diretamente. Como indica o título, a "culpa" (da Conquista do México) não foi da mulher indígena, como assinalou a historiografia tradicional mexicana, mas foi pela aliança que os tlaxcaltecas ${ }^{3}$ fizeram com Hernán Cortés, e da junção de forças deles, que deram aos espanhóis a vitória na Conquista do império asteca. A narrativa descreve dois tempos - um atual e outro que se volta para a época do encontro das culturas indígena e espanhola, permitindo que a análise aqui exposta seja confirmada. Assim sendo, apesar de não nomear Malinche ou fazer uma referência direta à Conquista, o conto permite essa conclusão, oferecendo um questionamento quanto à interpretação do mito de Malinche, principiando um movimento de problematização do ponto de vista nacionalista do século XIX sobre a "traição" de Malinche e as suas consequências.

${ }^{3}$ Segundo o Diccionario de Historia cultural de la Iglesia en América Latina "La nación tlaxcalteca estaba contecas quisier cus aztecas quisien edificaron puntos estratégicos de defensa, inicián Tose desde entono los tlaxcaltecas se reusaron y edificaron puntos estratégicos de defensa, iniciándose desde entonces un estado de 
Rosario Castellanos foi escritora e ensaísta, escrevendo textos sobre a condição submissa das minorias, especialmente das mulheres e dos indígenas. Dentre os vários textos em que revisa e re-interpreta a história de mulheres mexicanas, destacamos, conforme o recorte que aqui fizemos para o nosso estudo, o poema "La Malinche", do poemário Poesía no eres tú (1972), e a obra teatral El eterno femenino (1975).

No poema, a autora inverte a voz narrativa de quem relata a história - já não é mais a voz do cronista Bernal Díaz del Castillo ou mesmo de algum outro autor da época, mas sim a da própria Malinche, dialogando com a tradição. E a voz feminina intensifica o drama da menina, cujo nome não aparece, que teve sua morte encenada pela mãe e padrasto e foi vendida como escrava. A voz da filha, ao relembrar as palavras da mãe, "Ha muerto" (Está morta), ressoa amargurada e trágica, bem diferente da Malinche representada nas crônicas, que encontra a mãe e a perdoa. Nesse sentido, a autora humaniza a personagem feminina, afastando-a da figura construída pela história, tornando-a uma pessoa dotada de palavras para contar a história de seu ponto de vista.

Dentro desse panorama, a obra teatral póstuma de Castellanos, El eterno femenino (1975), vem corroborar com a construção desse novo itinerário. $O$ primeiro ato mostra uma personagem (fictícia), Lupita, fazendo um penteado para o seu casamento e no salão há um aparelho que faz a cliente dormir/ sonhar enquanto o cabelo seca. No segundo ato, em um de seus sonhos, Lupita encontra algumas célebres figuras históricas (todas elas mulheres como Eva Perón, La Malinche, Sor Juana Inés de la Cruz ou a Imperatriz Carlota) que aparecem em uma espécie de museu de cera. Cada uma dessas mulheres vai ganhando vida ao longo da obra e elas relatam a sua versão da história do momento em que viveram.

A Malinche de Castellanos não é representada como uma mulher subalterna aos espanhóis, infiel a seu povo e apaixonada por Cortés. No texto ficcional, a personagem ganha voz para proferir o seu discurso, sendo uma mulher valente, que soube utilizar a história ao seu redor para cumprir uma espécie de vingança pessoal (ser escrava dos astecas), tornando-se mentora intelectual de Cortés - cujo relacionamento passa longe do romantismo criado pela historiografia nacional.

Dentro desse panorama, encontramos outros textos, narrativos e teatrais, cujas autoras foram mencionadas anteriormente, com a proposta de apresentar uma re-leitura da imagem de Malinche: Malintzin y el Señor Malinche (1995), de Helena Alberú de Villava; Amor y conquista. La novela de Malinalli mal llamada la Malinche (1999) de Marisol Martín del Campo; El sueño de la Malinche (2000), de Marcela del Río; e um texto teatral posterior à obra de Esquivel, La verdadera historia de la Malinche (2009), de Fanny del Río.

Sobre o romance da escritora Alberú de Villava, a pesquisadora Beatriz Aracil (2014, p. 24) resume o seu intento de trazer a personagem histórica para a literatura:

es más bien un recorrido por principales acontecimientos de la conquista que intenta conjugar cierta atención a la "visión de los vencidos" con una imagen romántica del personaje heredada de autores como Gómez de Orozco y un intento de «valorar más objetivamente la importancia de esta excepcional mujer en las difíciles tareas de la Conquista y de la fundación de nuestra "nacionalidad".

Já em Amor y conquista, de Marisol Martín del Campo, percebemos a presença da perspectiva feminina em seu narrador, ou melhor, em sua narradora: Ozla, uma fiel assistente de Malinalli (como a personagem histórica é chamada ao longo do romance). Além da perspectiva do olhar da mulher, é nítida a consciência de Malinalli sobre a inferioridade da mulher na sociedade (indígena e espanhola) e é no poder da palavra que a personagem irá encontrar uma maneira de suplantar a submissão frente aos homens. 
A história do drama de Marcela del Río, El sueño de la Malinche - Sueño histórico-dramático en dos actos, é a rodagem de um filme sobre a história da Conquista do México. A técnica dialógica utilizada pela autora põe em evidência dois momentos históricos, cada qual com uma versão distinta de Malinche: no momento atual, ela é a traidora, e no passado é a Malintzin, uma heroína que lutou contra o conquistador de seu povo, Moctezuma. Para encenar as duas visões, aparecem na obra duas personagens distintas: uma que é, ao mesmo tempo, a atriz Aurora que interpreta Malintzin no filme e a segunda que é apenas Malintzin. Essa segunda personagem entra em cena para dialogar com o diretor do filme e expor uma visão muito diferente da visão da Malinche contemporânea. Aqui ela não é uma mulher submissa, que aceita a vontade do homem espanhol e que desconhece a importância de seu papel como intérprete. Ao contrário, ela é consciente de que não havia identidade de nação, de "raça" e de "indígena". Ao dar voz a personagem Malinche, Del Río permite que haja outras explicações para atos tidos como polêmicos de sua personagem histórica.

Embora o nosso propósito aqui seja sinalizar como a obra Malinche, de Laura Esquivel, publicada em 2006, configura-se como uma sequência das obras literárias que, desde o final do século $\mathrm{XX}$, problematizam a representação da personagem histórica, podemos destacar aqui o romance epistolar de Fanny del Río, La verdadera historia de la Malinche, publicado posteriormente ao romance de Esquivel, em 2009. Apesar de seguir uma narração clássica dos eventos descritos nas crônicas, também realça o papel de Malinche como "tradutora de dois mundos" e outorga a palavra à personagem por meio das cartas dirigidas a seu filho Martín (fruto da união dela com Cortés), nos quais ela justifica seus atos.

Traçado esse panorama da literatura contemporânea escrita por mulheres no México, tendo Malinche como personagem literária, vamos nos ater ao corpus literário de nossa análise. A autora Laura Esquivel ficou conhecida pelo livro (e filme) Como agua para chocolate (1989), que já trazia como temática a luta das personagens femininas contra os conceitos patriarcais e o conflito pela liberdade da mulher. Em Malinche, ela descreve a personagem histórica por meio do ponto de vista da mulher para explicar os atos da personagem histórica, justificando seu comportamento frente aos espanhóis e, assim, dar continuidade às concepções de literatura escrita por mulheres da terceira fase de Showalter.

Além do viés da Crítica Literária Feminista, o livro de Esquivel também pode ser analisado pelos estudos que focam as relações entre literatura e história, pois o enredo é traçado pelas fronteiras diluídas de história e ficção, tematizando o passado mexicano de forma consciente e questionadora, trazendo ao leitor uma leitura diferente daquela que a historiografia impôs, especialmente no século XIX. Nessa perspectiva, podemos destacar um gênero literário muito próspero na América Latina, em especial a partir dos meados do século XX, que se chama romance histórico, gênero pautado na maioria das vezes

por la voluntad de re-fundar de la nación, de re-escribir la historia desde la perspectiva de los distintos actores que la hicieron, o que padecieron silenciosamente sus efectos, de revisar tanto la historia oficial de cada país como la de América Latina, para alcanzar la verdadera independencia del pensamiento. (CUNHA, 2004, p. 15)

São várias as pesquisas e estudos sobre o romance histórico contemporâneo, mas praticamente é consenso que sua característica marcante é a releitura crítica da história (cf. AÍNSA, 1991; MENTON, 1993; ESTEVES, 2010), de modo a elucidar que o passado histórico não pode ser reconstituído em sua integralidade porque seu resgate provém da leitura e interpretação do historiador a partir de vestígios e fragmentos encontrados como textos escritos, fotos, vídeos, relatos orais, etc. Por isso, a literatura 
reivindica a possibilidade de proporcionar uma leitura do passado, utilizando-se dos mesmos vestígios e criando um discurso narrativo no qual propõe uma interpretação a partir de um ponto de vista distinto. Muitas vezes, esse novo ângulo deriva de grupos que estiveram à margem da história, como as mulheres.

É por este caminho que a ficção de Esquivel adentra na história de Malinche: para reescrever e revisar a história oficial de modo a proporcionar outras leituras sobre as ações da personagem, com o intuito de romper a visão hegemônica construída pelos nacionalistas. A narrativa tem como foco a mulher e seus sentimentos, partindo do nascimento de Malinche, de sua infância ao lado da avó, passando pelos eventos da Conquista do México e terminando com a morte da protagonista, de modo a evidenciar uma ampla transformação não só na vida social de Malinche, mas principalmente na vida interior, nas suas concepções e convicções. Assim, o romance revela uma personagem mais humana, com seus sentimentos e conflitos internos, expondo as particularidades que a levaram a ser a intérprete de Cortés, a amá-lo e, por fim, rejeitá-lo. Devemos salientar aqui que o romance não particulariza somente a mulher, pois a vida de Cortés também é descrita com minúcia, revelando um lado pessoal que não está exposto nas crônicas.

Uma particularidade interessante da obra é não nomear a protagonista como Malinche. Ao longo de todo o enredo seu nome é Malinalli. O próprio texto explica que o nome Malinche era um "apodo que le habían adjudicado a Hernán Cortés, por estar siempre a su lado. Malinche de algún modo significaba 'el amo de Malinalli'" (ESQUIVEL, 2006, p. 98). Isto posto, devemos perguntar por que o romance se chama "Malinche"? Está se referindo a Cortés ou à sua intérprete que ficou conhecida com tal apodo? Talvez, aos dois ao mesmo tempo. Não é possível separar a história de ambos, ou seja, é impossível falar da Conquista do México sem se referir aos dois, pois cada um tem sua colaboração nos acontecimentos. Podemos dizer que não existe Cortés sem Malinche e não há Malinche sem Cortés. O que pode ser questionado aqui é por que ela, a mulher, não teve seu nome original preservado, sendo identificada pela alcunha que os indígenas deram a ele. Ao se tornar "Malinche", a indígena perde a sua identidade pessoal. Talvez seja por esse motivo que Laura Esquivel pensou em nomear a sua protagonista, ao longo de toda a narrativa, com seu nome original.

E não foi somente o nome original que Laura Esquivel resgatou de sua protagonista, mas também a cultura e religiosidade indígenas, com toda a riqueza de símbolos que elas contêm. É por isso que desde as primeiras páginas, a narrativa está impregnada da presença dos elementos da natureza e da invocação/lembrança dos deuses, recriando um ambiente que contrasta com o contexto europeu/cristão, em um entrechoque de culturas, crenças, convicções...

No primeiro capítulo, o narrador nos apresenta o nascimento de Malinalli ${ }^{4}$ e os primeiros dias de Cortés em terras do Novo Mundo. As circunstâncias que envolvem a natividade de Malinalli estão envoltas nos rituais de seu povo e o que se sobressai é a profecia de seu pai:

Hija mía, vienes del agua, y el agua habla. [...] Tu palabra estará en el agua y será espejo de la lengua. Tu palabra tendrá ojos y mirará, tendrá oídos y escuchará, tendrá tacto para mentir con la verdad y dirá verdades que parecerán mentiras. Y con tu palabra podrás regresar a la quietud, a principio donde nada es, donde nada está, donde todo lo creado vuelve al silencio, pero tu palabra lo despertará y habrás de nombrar a los dioses y habrás de darle voces a los árboles, y harás que la naturaleza tenga lengua y hablará por ti lo invisible y se volverá visible en tu palabra (ESQUIVEL, 2006, p. 16).

4 Já que a autora mexicana fez questão de nomear sua personagem de Malinalli e não Malinche, ao nos referir à protagonista do romance, preservaremos a escolha de Esquivel. 
Por meio das palavras do pai de Malinalli, a narrativa antecipa o papel da recém-nascida no futuro, como se fosse uma deusa, já que o mundo seria recriado por suas palavras. Aliás, o texto de Esquivel está sempre reforçando o papel e a importância da linguagem/palavra para formar um mundo novo. Talvez essa tenha sido a maneira encontrada pela autora para dizer às mulheres que elas podem mudar a situação de subordinação frente aos homens através da linguagem, denunciando as circunstâncias em que se encontram e procurando novos caminhos. É pela palavra que Esquivel e muitas outras escritoras têm revelado ao mundo como as mulheres/indígenas foram silenciadas pela ideologia patriarcalista, como foram omitidas no discurso histórico e pela cultura de seu país, bem como tem requerido o direito de fala da mulher, hoje e no passado. A pesquisadora Salete Santos (2010, p. 61), em um texto sobre o romance de Esquivel, resume o assunto:

Malinalli encontra na palavra proferida uma alternativa de vivência, exercendo domínio sobre indígenas e espanhóis como tradutora e intérprete de línguas e costumes diversos. Nesse percurso, encontra um lugar naquele universo de exclusão e empreende uma trajetória para o encontro de si mesma. [...] a jornada da protagonista Malinalli, na obra Malinche, traz à luz os sentimentos de uma mulher que sonha com a humanização da religião de seu povo e com a possibilidade de sua completude como ser humano.

Retornando à trama ficcional, é interessante notar que a segunda parte do capítulo inicial relata como Cortés se sente bem ao entrar em contato com a natureza do Novo Mundo e que, após ser picado por um escorpião, agonizar e delirar por três dias, sonhando com uma serpente que voava pelos ares (uma referência a Quetzalcóatl), ele renasce com uma nova força que ninguém podia dizer de onde a havia tirado. Desse modo, o enredo vai sendo entrelaçado com as histórias da vida de Malinalli e de Cortés durante a Conquista do México, revelando o que cada personagem espera dos acontecimentos e como se dá a evolução (pessoal, social) de cada um deles ao final da história. Dessa maneira, o narrador entrelaça as narrações da vida de Cortés e de Malinalli, de forma a evidenciar, no enredo, que ambos são indissociáveis, como dois lados da mesma moeda.

É importante destacar, aqui, a expectativa de Malinalli ao conhecer seus novos donos, enquanto o narrador especifica convicções da personagem sobre o povo asteca (los mexicas), governado por Moctezuma, e sobre o deus Quetzalcóatl, a quem os povos subjugados esperam o regresso com ansiedade, pois somente assim

modificaría por completo el rumbo de todos los pueblos que los mexicas tenían sojuzgados. Malinalli estaba en total desacuerdo con la manera en que ellos gobernaban, se oponía a un sistema que determinaba lo que una mujer valía, lo que los dioses querían y la cantidad de sangre que reclamaban para subsistir.

[...] A Malinalli le urgía tanto el regreso del señor Quetzalcóatl —principal opositor de los sacrificios humanos- que hasta estaba dispuesta a creer que su dios tutelar había elegido el cuerpo de los recién llegados a estas tierras para que ellos le dieran forma a su espíritu, para que ellos lo albergaran en su interior (ESQUIVEL, 2006, p. 24).

O interessante, como diz a história e a tradição oral, é que os espanhóis chegaram a terras mexicanas exatamente no ano que o deus Quetzalcóatl dissera que retornaria. Além disso, as representações que os povos faziam de seu deus mostravam que ele era branco, alto e barbudo, bem diferente (fisicamente) do povo indígena. Ou seja, a obra desenha um possível caminho que Malinche, a figura histórica, pode ter traçado: de acreditar que os recém-chegados eram mesmo (enviados dos) deuses. Na narrativa de Esquivel, a protagonista deseja realmente que tudo seja verdade para ter a liberdade para si, para não ser mais escrava de mercadores (maias ou astecas). Nesse panorama, o romance apresenta uma justificativa para os atos da heroína histórica ao proporcionar à personagem fictícia que declare 
seus pensamentos. Na ficção, a autora permite que a mulher tenha voz para expor um ângulo não revelado pela história, outorgando ao leitor mais um ponto de vista e muitos questionamentos sobre o que teria sido a "traição" de Malinche.

Uma pessoa muito influente na vida da personagem Malinalli foi sua avó paterna. Foi ela quem fez o parto, participou do ritual do nascimento e criou a menina até os cinco anos (quando veio a falecer). Nos momentos de conflito, a personagem recorda a avó e seus ensinamentos, o que lhe conforta e dá coragem para seguir em frente. A sabedoria de Malinalli foi herdada de sua progenitora, que lhe ensinou a desenhar e decifrar os códices e desenvolver a memória e a expressão oral. Assim, o romance explica a facilidade de Malinalli em interpretar e em aprender novos idiomas, o que lhe abrirá novos caminhos em seu futuro.

A habilidade oral que Malinalli possuía levou-a sair do estado de escravidão em que se encontrava para desempenhar o papel de intérprete daquele que, até então, era tido como (enviado de) deus. Foi por seu esforço e capacidade que a personagem evoluiu socialmente:

Ella, la esclava que en silencio recibía órdenes, ella, que no podía ni mirar directo a los ojos de los hombres, ahora tenía voz, y los hombres, mirándola a los ojos, esperaban atentos lo que su boca pronunciara. Ella, a quien varias veces habían regalado, ella, de la que tantas veces se habían deshecho, ahora era necesitada, valorada, igual o más que una cuenta de cacao (ESQUIVEL, 2006, p. 73).

Nesse sentido, a personagem sai de um estado de subordinação, de reclusão à esfera privada e aos papéis domésticos, e passa a ganhar consideração dos homens por causa de sua palavra. Ela se desloca do silenciamento e esquecimento que foram impostos às mulheres à expressividade e à presença feminina na história. A sua evolução não é somente exterior, mas principalmente interior, quando adquire consciência do poder da palavra:
Pronto aprendió que aquel que maneja la información, los significados, adquiere poder, y descubrió que al traducir, ella dominaba la situación y no sólo eso, sino que la palabra podía ser un arma.

$[\ldots]$

Al traducir, Malinalli podía cambiar los significados e imponer su propia visión de los hechos y, al hacerlo, entraba en franca competencia con los dioses, lo cual la aterrorizaba (ESQUIVEL, 2006, p. 71-73).

Nesse contexto, Malinalli é comparada aos deuses, já que tanto na Bíblia como no Popol Vuh (o livro sagrado dos maias), o mundo foi criado a partir da palavra. No caso da protagonista da obra de Esquivel, o mundo criado não é nem o indígena nem o cristão: é a mestiçagem de ambas culturas, religiões, raças, etc. Aqui percebemos o intento da escritora em ressaltar a presença feminina na construção da história e da identidade de seu país, não como traição ou covardia como foi pintada por muitos autores e estudiosos, mas como um agente ativo e sagaz, com habilidade de falar outras línguas e, assim, se distinguir das demais indígenas.

Um importante episódio na história da Conquista do México se passa no povoado de Cholula. A versão mais conhecida é que uma senhora idosa teria revelado a Malinche que existia um complô entre os habitantes de Cholula para entregar os espanhóis aos astecas. Malinche teria alertado Cortés que revidou a rebelião com uma represália. Em sua pesquisa, Cristina González Hernández (2002, p. 106) comenta tal episódio, baseando-se na obra de Alfonso Toro, revelando que não se pode verificar se a história da idosa existiu ou não, mas que Malinche, na historiografia, acaba levando o peso dos mortos, culpa que é compartilhada com os tlaxcaltecas que ajudaram Cortés na retaliação.

$\mathrm{Na}$ narrativa de Esquivel, o relato constitui um importante salto na vida pessoal de Malinalli e na sua percepção sobre o mundo ao seu entorno. Ao desenrolar a trama, ela começa a perceber certas atitudes dos espanhóis 
que a leva a questionar se realmente eles eram deuses, já que foi com frieza e crueldade que eles mataram os indígenas. Suas suspeitas iniciam-se na matança em Cholula, que Cortés tentou explicar por razões de infidelidade ao verdadeiro Deus e como ação preventiva e de represália, para que outros povos não se rebelassem contra eles. Malinalli também começou a duvidar das suas crenças, pois seus deuses não deixariam que os cholultecas sofressem um ataque tão tremendo sem revidar a afronta. Mesmo com seus questionamentos, uma coisa era certa: Malinalli se sentiu culpada pelo massacre, mesmo tentando desculpar-se a si mesma:

La Malinalli de ahora era otra, el río era otro, Cholula era otra, Cortés era otro. [...] ¿Qué venía como respuesta a este horrendo asesinato del que ella se sentía tan culpable? Trataba de disculparse pensando que, aunque ella no le hubiera confiado a Cortés la plática que había sostenido con la mujer cholulteca [...], Cortés se habría enterado de los planes por otros medios [...]. También le habían informado los tlaxcaltecas que en las afueras de la ciudad había una guarnición de entre quince y veinte mil guerreros de Moctezuma, cosa que nunca se comprobó; lo único real era que tanto españoles como tlaxcaltecas, en dos días, habían matado a más de seis mil indígenas (ESQUIVEL, 2006, p. 71-73)

A narrativa segue, após os fatos de Cholula, com a chegada de Cortés e seu exército em Tenochtitlan, capital do império asteca. Eles foram recebidos por Moctezuma e se hospedaram no palácio real. Nesse momento, a personagem começa a questionar (para si mesma) as "verdades" de seu mundo. Por exemplo, em relação à divindade do rei asteca, Moctezuma, que ninguém podia olhar diretamente no rosto, Malinalli entende que era uma mentira, já que pode olhá-lo e conversar com ele diretamente, sem que nada a atingisse ou que ela sofresse algum dano. Ela percebe que o imperador é um ser humano como os demais e, assim, descobre que seu mundo já não é mais o mesmo, já não é mais aquilo que acreditava que fosse.
Aos poucos, ela compreende a situação em que está inserida, que seus atos e palavras já não podem auxiliar Moctezuma e que já não havia como impedir o desenrolar dos acontecimentos:

[...] durante el primer encuentro entre Moctezuma y Cortés, ella había sido la traductora y durante su actuación había mirado directo a los ojos de Moctezuma, el máximo gobernante. [...] Lo que nunca esperó fue que Moctezuma depusiera su trono a favor de Cortés y que ella, por ser la traductora, fuera quien prácticamente le hubiera dado el reino a Cortés. Tampoco se imaginó que al hacerlo experimentaría un dolor tan profundo. Era muy triste ver que su fe no tenía nada que hacer al lado de la de Moctezuma (ESQUIVEL, 2006, p. 124).

Se, no começo, as palavras de Malinalli lhe proporcionavam gozo e glória, a partir desse momento a levam para a tristeza, pois não consegue dizer a Moctezuma o que tinha descoberto com os últimos acontecimentos: que os espanhóis não eram deuses e nem seus enviados. Sua angústia aumentou com a chamada "Matanza del Templo Mayor" e culminou com a morte de Moctezuma. $\mathrm{O}$ caminho percorrido pela protagonista vai do amor e contemplação até o ódio a Cortés, que foi intensificado por suas últimas atitudes em relação a ela: após o nascimento de Martin (filho dela com Cortés), o conquistador espanhol fez com que ela se casasse com um soldado seu, Jaramillo, e morasse longe da criança.

Nessa perspectiva, todos os méritos, as virtudes, tudo o que dignificou Malinalli por sua habilidade oral e pelo poder de sua palavra, tornou-se, ao final, impotência, inutilidade e motivo de destruição. Ela que havia acreditado nos seus deuses e em Cortés como enviado deles, que se dedicou a buscar sua liberdade e servir àqueles a quem ela tinha fé, constata que seu mundo está arruinado: "La lengua era la culpable de todo. Malinalli había destruido el imperio de Moctezuma con su lengua. Gracias a sus palabras, Cortés se había hecho con aliados que aseguraron su conquista. Decidió entonces castigar el instrumento que había creado ese universo" (ESQUIVEL, 2006, p. 163). 
A língua, que foi motivo de ascensão para Malinalli, uma esperança para a liberdade, agora torna-se fracasso, inutilidade, tristeza. A protagonista é consciente dessas ações e se culpa por não conseguir reverter a situação. A única atitude que pode tomar é perfurar a língua para não mais ser a intérprete de Cortés.

Por fim, já casada com Jaramillo e mãe de dois filhos, Malinalli recebe a visita de Cortés. Enquanto ela tratava de se reconciliar com os deuses e consigo mesma, retomando a convivência com o filho, Cortés vai visita-la. Se Malinalli estava em busca de paz, superando todo o mal que havia presenciado em sua vida, Cortés se afundava em um mar de crimes: infidelidade aos reis, tirania e crueldade na guerra, enriquecimento ilícito, apropriação de bens alheios, além de ser réu na causa da morte de sua esposa espanhola. Mesmo com tudo o que estava sofrendo, Malinalli não pode se calar, ela precisava e teve a chance de dizer a Cortés tudo o que havia guardado durante os momentos que passou a seu lado:

La peor de todas las enfermedades nacidas de tu ambición no ha sido la viruela, ni la sífilis. La más grave de todas las enfermedades son tus malditos espejos. Su luz hiere, como hiere tu filosa espada, como hieren tus crueles palabras, como hieren las bolas de fuego que tus cañones escupieron sobre mi gente. [...]En las imágenes de tus espejos hay gritos y crímenes devorados por el tiempo. Tus espejos distorsionan y enloquecen al ser que se mira en ellos; lo contagian de miedo, le deforman el corazón, lo destrozan, lo sangran y lo maldicen; lo engañan con su alma escurridiza, quebradiza, falsa. Mirarte tanto tiempo en tus espejos te ha enfermado, te ha mostrado una gloria y un poder equivocado. [...] iTus espejos son tan terribles como tú! Lo que más odio, Hernán, es haberme mirado en tus espejos. En tus negros espejos» (ESQUIVEL, 2006, p. 182).

Podemos afirmar, com base em nossa análise, que a personagem passa por uma reviravolta em sua vida social e pessoal, passando por conflitos interiores e ganhando novas experiências e uma consciência cada vez mais nítida sobre os espanhóis e sobre seu próprio mundo. Podemos recordar aqui as palavras de Santos (2010, p. 61) em um texto sobre o romance de Esquivel, no qual comenta que a personagem Malinalli passa a viver "uma alternativa de vivência" desde que descobriu o poder da palavra e "encontra um lugar naquele universo de exclusão e empreende uma trajetória para o encontro de si mesma".

Podemos comparar a narrativa como um romance de formação - pois o desenvolvimento interior da personagem se dá na medida em que ela entra em confronto com os acontecimentos ao seu redor, questionando e tomando consciência cada vez maior dos seus atos e do contexto em que está inserida - e a consequência é a priorização da voz interior, de seu individualismo e subjetividade (cf. LOBO, Bildungsroman). Por isso, aos poucos, vai atuando consciente e ativamente no encontro dos dois mundos, indígena e espanhol, deixando sua marca na história. Nessa viagem ao seu interior, Malinalli adquire um discernimento maior de si mesma e do mundo ao seu redor.

É por esta trajetória, mostrando os conflitos interiores da protagonista, que Laura Esquivel problematiza, questiona e descontrói a imagem de traidora que os historiadores e críticos da cultura do México atribuíram a Malinche. Tal desconstrução se dá por meio da voz e do ponto de vista da mulher: ao mesclar em seu texto a literatura, a história e a memória, a autora mexicana proporciona ao leitor uma nova configuração do mito de Malinche, ela cria uma "história híbrida", segundo o termo cunhado por Perkowska (2008, p. 42):

[...] los novelistas dibujan un nuevo mapa para el concepto de la historia y su discurso. Vista desde esta perspectiva, la novela histórica latinoamericana no cancela la historia sino que redefine el espacio declarado como "histórico" por la tradición, la convención y el poder, postulando y configurando en su lugar las historias híbridas que tratan de imaginar otros tiempos, otras posibilidades, otras historias y discursos. 
Em seu livro América (2006), André Trouche comenta que a relação ficção e história na América Latina sempre foi estreita e os primeiros textos aqui escritos (por europeus) costumam ser estudados tanto pela historiografia quanto pela literatura. Por isso, por ter nascido atrelada à história que a literatura provoca o diálogo com a história de forma "transgressora", pois implica oferecer novas visões sobre o discurso instaurado, quebrando a hegemonia desse e criando uma pluralidade de vozes sobre o passado.

Nesse contexto, podemos afirmar que o romance Malinche, bem como as demais obras aqui analisadas, apresentam versões que desconstroem a ideologia patriarcal que erigiu o mito negativo desse ícone da cultura mexicana e também que cada autora permite que suas personagens tenham voz e reivindiquem uma interpretação diferente para as ações de Malinche no passado. Deste modo, a narrativa de Laura Esquivel acompanha tanto as concepções contemporâneas de escrita feminina, como as relações de literatura e história.

\section{Referências}

AINSA, Fernando. La nueva novela histórica latinoamericana. Plural, México, v. 240, p. 82-85, 1991.

ALBERÚ DE VILLAVA, Helena. Malintzin y el Señor Malinche. México: EDAMEX. 1995.

ARACIL, Beatriz. La Malinche: historia y mito en dos novelas mexicanas contemporáneas. In: EUDAVE, Cecilia; ORTIZ, Alberto; ROVIRA, José Carlos (Ed.). Mujeres novohispanas en la narrativa mexicana contemporánea. Alicante: Universidad de Alicante (Cuadernos de América sin nombre), 2014. p. 13-41. Disponível em: <https://rua.ua.es/dspace/ bitstream/10045/36879/1/Mujeres_novohispanas.pdf>. Acesso em: 03 ago. 2016.

BIBLIA. Bíblia sagrada. São Paulo: Ed. Ecumênica, 1980

CASTELLANOS, Rosario. El eterno feminino. México: Fondo de Cultura Económica, 1996. CASTELlanOS, Rosario. Malinche. In: Poesía no eres tú. México: Fondo de Cultura Económica, 1972. p. 285-27.
CUNHA, Gloria da (Org.). La narrativa histórica de escritoras latinoamericanas. Buenos Aires: Corregidor, 2004

CYPESS, Sandra Messinger. La Malinche in Mexican literature: from history to myth Austin: University of Texas Press, 1991.

DE LUCA, Dina. México. In: CUNHA, Gloria da (Org.). La narrativa histórica de escritoras latinoamericanas. Buenos Aires: Corregidor, 2004.

DEL RÍO, Fanny. La verdadera historia de la Malinche. México: Grijalbo, 2009.

DEL RÍO, Marcela. El sueño de la Malinche - Sueño histórico-dramático en dos actos Disponível em: <http://seminariodeculturamexicanacuernavaca.org/integrantes/ m_rios/17.pdf>. Acesso em: 2 ago. 2016.

DÍAZ DEL CASTILLO, Bernal. Historia verdadera de la conquista de la nueva España. Buenos Aires: Editorial Universitaria de Buenos Aires, 1964.

ESCUDERO-ALIE, María Elvira Luna. El Eterno Femenino, de Rosario Castellanos Hispanista, n. 17. Abril/maio/junho de 2004. Disponível em: <http://www.hispanista. com.br/revista/artigo148esp.htm>. Acesso em: 15 jul. 2016.

ESQUIVEL, Laura. Malinche. Buenos Aires: Alfaguara, 2006.

ESTEVES, Antonio R. O romance histórico brasileiro contemporâneo (1975-2000). São Paulo: Ed. UNESP, 2010.

FLORA, Luisa. Bildungsroman. In: CEIA, Carlos. E-Dicionário de termos Literários. Disponível em: <http://edtl.fcsh.unl.pt/business-directory/6102/bildungsroman/>. Acesso em 01 ago. 2016.

GARCIA, ANA Cruz. Re(de)generando identidades. Locura, feminidad y liberalización en Elena Garro, Susana Pagano, Ana Castillo y María Amparo Escandón. Berlin: Peter Lang Pub, 2009.

GARRO, Elena. La culpa es de los tlaxcaltecas. In: La semana de colores. México: Grijalbo 1989. p. 59-72.

GLANTZ, Margo (Ed.). La Malinche, sus padres y sus hijos. México: Taurus. 2001.

GONZÁLEZ HERNÁNDEZ, Cristina. Doña Marina (La Malinche) y la formación de la identidad mexicana. Madrid: Ediciones Encuentro, 2002.

HOLLADAY, Kandace Kane. Visión histórico-política de México a través de cuatro dramaturgas mexicanas. Tese. University of Tennessee, 2011. 
MARTÍN DEL CAMPO, Marisol. Amor y conquista. La novela de Malinalli, mal llamada la Malinche. México: Planeta-Joaquín Mortiz. 1999.

MEDEIROS-LICHEM, María Teresa. La voz femenina en la narrativa latinoamericana. Chile, Editorial Cuarto Propio, 2006. Disponível em: <https://books.google.com.br/boo $\mathrm{ks} ? \mathrm{id}=\mathrm{sLNjC} 3 \mathrm{cYwAMC} \& \mathrm{pg}=\mathrm{PA} 47 \& \mathrm{hl}=\mathrm{pt}-\mathrm{R} \&$ source $=\mathrm{gbs} \_$toc_r\&cad $=3 \# \mathrm{v}=$ onepage $\& \mathrm{q} \& \mathrm{f}$ =false $>$. Acesso em: 30 jul. 2016.

MENTON, Seymour. La nueva novela histórica de la América Latina, 1949-1992. México: Fondo de Cultura Económica, 1993.

NAVARRO, Márcia H. Por uma voz autônoma: o papel da mulher na história e na ficção latino-americana contemporânea. In: NAVARRO, Márcia H. (Org.). Rompendo o silêncio: gênero e literatura na América Latina. Porto Alegre: Editora da Universidade/UFRGS, 1995. p. 11-55.

NAVARRO, Márcia H. Re-escrevendo o feminino: a literatura latino-americana atual em perspectiva. In: LIMA, Tereza M. O.; MONTEIRO, Maria Conceição (Org.). Figurações do feminino nas manifestações literárias. Rio de Janeiro: Caetés, 2005. p. 197-217.

NAVARRO, Márcia Hoppe. El mito de la Malinche en la obra reciente de escritoras hispanoamericanas. En: ZABALGOITIA HERRERA, Mauricio (Ed.); USANDIZAGA, Helena (Dir); BUSTAMANTE, Fernanda (Coord.). Mitologías hoy 4. Fundaciones, cosmogonías y personajes: Mito prehispánico en literaturas latinoamericanas. Serie Los tiempos del mito, Barcelona, n. 3, p. 5-15, 2011. Disponível em: <http://revistes.uab.cat/mitologias/ article/viewFile/v4-hoppe/14>. Acesso em: 28 fev 2017

PERKOWSKA, Magdalena. Historias híbridas: la nueva novela histórica latinoamericana (1985-2000) ante las teorías posmodernas de la historia. Madrid: Iberoamericana; Frankfurt am Main: Vervuert, 2008.

PINTO, Céli Regina Jardim. Feminismo, história e poder. Revista de Sociologia e Política, Curitiba, v. 18, n. 36, p. 15-23, jun. 2010.

POPOL vuh. Madrid: Mestas, 2007.

SANTOS, Salete Rosa Pezzi dos. A história de Malinche revisitada. In: ZINANI, Cecil J. A.; SANTOS, Salete R. P. dos (Org.). Mulher e literatura: história, gênero e sexualidade. Caxias do Sul: Educs, 2010. p. 51-62.

SHOWALTER, Elaine. A literature of their own. In: EAGLETON, M. Eagleton. Feminist literary theory: a reader. Blackwell: Cambridge, 1986, p. 11-15.
Tlaxcalteca. In: Diccionario de Historia Cultural de la Iglesia en América Latina. Disponível em: <http://www.enciclopedicohistcultiglesiaal.org/diccionario/index.php/ TLAXCALTECAS>. Acesso em: 3 mar. 2017

TROUCHE, André. América: história e ficção. Niterói, EDUFF, 2006.

ZOLIN, Lúcia Osana. Literatura de autoria feminina. In: BONNICI, Thomas; ZOLIN, Lúcia Osana (Org.). Teoria literária: abordagens históricas e tendências contemporâneas, 2. ed. Maringá: Eduem, 2005. p. 275-83.

Recebido em 08/08/2016.

Aceito em 11/03/2017. 